\title{
Pengaruh Murattal Alquran Terhadap Tingkat Stres Mahasiswa Muslim di Yogyakarta
}

\author{
Anisa Zahra Wijayanti Nugroho ${ }^{1}$ E Sri Kusrohmaniah ${ }^{2}$ \\ 1,2Fakultas Psikologi Universitas Gadjah Mada
}

\begin{abstract}
This study aimed to see the effect of the murattal Alquran on the level of individual stress. Hypothesis proposed in this research that there was influence of murattal Alquran in change of stress level experienced by experiment group and there was difference of stress levels between experiment and control group. The experimental design used was randomized pretest and posttest control group design. The subjects consisted of 45 participants age 18-22 years old, then divided into experiment group $(n=23)$ and control group $(n=22)$. The stress level was measured by stress subscale krom Depression, Anxiety, Stress Scale (DASS). Data were analyzed using ANOVA mixed method and the result showed the value of $F=10.386(p<0.05)$. That means, there was a significant change after listening to the Quranic murattal. The change in pretest and posttest score in the experimental group was shown with $F=-5.957(p<0.05)$ and the control group had $F=-$ $1.136(p>0.05)$, meaning that there was a significant difference in the reduction of stress score of both groups. Moreover, the muratal Quran had an influence on changes in stress levels on the subject with an effective contribution of $19.4 \%(E T A 2=0.194)$. Thus, the research hypothesis was accepted.
\end{abstract}

Keywords: Alquran; coping; murattal; stress

Abstrak. Penelitian ini dilakukan untuk melihat pengaruh murattal Alquran terhadap tingkat stres individu. Hipotesis penelitian ini yaitu terdapat pengaruh murattal Alquran dalam perubahan tingkat stres yang dialami kelompok eksperimen dan ada perbedaan tingkat stres antara kelompok eksperimen dengan kelompok kontrol. Rancangan eksperimen yang digunakan adalah randomized pretest and posttest control group design. Subjek penelitian terdiri atas 45 partisipan berusia 18-22 tahun dan terbagi ke dalam kelompok eksperimen $(n=23)$ serta kelompok kontrol $(n=22)$. Tingkat stres diukur dengan Depression, Anxiety, Stress Scale (DASS) subskala stres. Data dianalisis menggunakan ANOVA mixed method. Hasil analisis menunjukkan nilai $F=10,386(p<0,05)$. Artinya, terdapat perubahan yang signifikan setelah mendengarkan murattal Alquran. Selain itu, perubahan skor pretest dan posttest pada kelompok eksperimen ditunjukkan dengan nilai $F=-5,957(p<0,05)$ dan pada kelompok kontrol memiliki nilai $F=-1,136(p>0,05)$, artinya terdapat perbedaan signifikan pada penurunan skor tingkat stres kedua kelompok. Murattal Alquran juga memiliki pengaruh terhadap perubahan tingkat stres pada subjek dengan sumbangan efektif 19,4\% (ETA2 =0,194). Dengan demikian, hipotesis penelitian dapat diterima.

Kata kunci: Alquran; koping; murattal; stress

Indonesia dikenal sebagai negara yang

${ }^{1}$ Korespondensi mengenai artikel ini dapat dilakukan melalui anisa_zahrawn@yahoo.co.id

2atau koes psi@ugm.ac.id memiliki tingkat religiusitas tinggi. Hal tersebut ditunjukkan oleh hasil survei dari Lembaga Survei Indonesia menunjukkan 
bahwa sebanyak 55,9\% masyarakat Indonesia rutin melakukan salat wajib lima waktu, 67,5\% rutin puasa Ramadan, dan 30,3\% sering melakukan salat sunah (Muhtadi \& Prasetyo, 2017). Najati (1985) mengatakan bahwa keimanan pada Tuhan dapat menguatkan manusia dalam menanggung beban kehidupan dan menjadi kekuatan rohani yang dapat menghindarkannya dari keresahan hidup. Di sisi lain, Data Riset Kesehatan Dasar 2013 menunjukkan bahwa gangguan mental emosional yang ditunjukkan dengan gejala seperti kecemasan dan depresi mencapai angka prevalensi sebesar $6 \%$ untuk usia 15 tahun ke atas, atau sejumlah 37.728 orang dari seluruh subjek yang dianalisis. Sedangkan, usia 15-17 tahun ke atas memasuki usia remaja akhir yang mana masa remaja merupakan bagian dari masa pencarian jati diri, eksplorasi, dan pengembangan diri (Santrock, 2014) dan umumnya telah menduduki bangku kuliah.

Kondisi ini tidak baik bagi Indonesia yang dikenal religius, namun memiliki prevalensi gangguan mental yang cukup mengkhawatirkan, terlebih lagi pada mahasiswa yang kerap disebut sebagai agen perubahan. Berbagai tuntutan eksternal seperti akademik, sosial, perubahan kehidupan, dan tuntutan internal seperti keinginan berprestasi yang tinggi dapat membuat mahasiswa merasa terbebani dan dapat berdampak pada kelelahan fisik, berupa turunnya daya tahan tubuh, maupun kelelahan mental, seperti emosi yang labil (Ruhmadi, Suwartika, \& Nurdin, 2014). Meski banyak gangguan psikologis yang dihadapi mahasiswa seperti depresi mayor, kasus bunuh diri, kecemasan, dan lainnya, namun ada kasus mendasar yang dapat menjadi penyebab dari gangguan psikologis tersebut, yaitu stres yang memiliki persentase $33 \%$ di kalangan mahasiswa pada umumnya (Grayson \& Meilman, 2006).

Stres didefinisikan sebagai pengalaman emosional yang negatif yang diikuti oleh perubahan fisiologis, kognitif, dan perilaku yang dapat diprediksi untuk kemudian menjadi arahan dalam menghindari kondisi penuh tekanan atau dibiarkan seperti apa adanya (Taylor, 2015). Stres merupakan bentuk stimulus yang diberikan oleh lingkungan dan memengaruhi kondisi seseorang (Brannon, Feist, \& Updegraff, 2013). Ketika stres, seseorang merasa tegang, gelisah, sulit rileks, sensitif, pusing, takut, kehilangan nafsu makan, sulit tidur di malam hari (Alatas, 2017). Hans Selye (Brannon et al., 2013) menjelaskan bahwa ada 3 tahapan yang terjadi ketika individu menghadapi stresor, yaitu alarm, resistance, dan exhaustion. Tahapan ini disebut sebagai general adaptation syndrome. Sedangkan Lazarus \& Folkman (1984, dalam Brannon et al., 2013) menjelaskan bahwa ketika menemui stresor, akan terjadi tiga penilaian dalam diri individu, yaitu penilaian primer, penilaian sekunder, dan penilaian ulang yang akan berpengaruh pada kondisi fisiologis tubuh.

Secara fisiologis, ketika individu sedang mengalami stres, terjadi peningkatan hormon adrenalin dan kortisol. Jumlah hormon adrenalin dan kortisol yang berlebih dapat membuat seorang individu memiliki detak jantung yang cepat, tekanan darah meningkat, membuat kepala pusing, menekan sistem imun, dan meningkatkan gula darah. Sedangkan secara psikologis, Brannon et al. (2013) menjelaskan bahwa ada tiga alternatif manajemen stres yang dapat dilakukan, yaitu dengan berlatih relaksasi, terapi kognitif keperilakuan, dan penyingkapan emosi.

Pada zaman modern ini, manusia hidup di lingkungan yang penuh 
persaingan dalam hal materi. Begitu pula para mahasiswa yang bersaing dalam bidang akademis maupun non-akademis. Kehidupan modern dapat membuat seseorang jauh dari Tuhan dan menderita penyakit jiwa (Najati, 1985). Warber, et. al, (2011, dalam Awa, 2014) mengatakan bahwa ketika seseorang jauh dari Tuhan maka emosi negatif seperti kemarahan, ketakutan, kecemasan, depresi, dan rasa putus asa dapat muncul dan memengaruhi kehidupan seseorang. Oleh karena itu, sangat mungkin kondisi kesehatan mental di Indonesia cukup buruk karena individu semakin dekat dengan dunia modern yang memiliki persaingan materi dalam berbagai bidang, namun semakin jauh dari nilai-nilai religiusitas dan etis (Sadeghi, 2011). Oleh karena itu, dibutuhkan nilai-nilai rohani yang didapat dari agama untuk mengatasi tekanan dan ketegangan yang dirasakan manusia saat ini (Najati, 1985).

Di sinilah peran dari murattal Alquran sebagai sebuah intervensi berbasis religiusitas dibutuhkan. Selain mudah dan aman, murattal Alquran berpengaruh terhadap salah satu gelombang otak, yaitu gelombang alpa. Gelombang alpa merupakan salah satu gelombang otak dengan frekuensi 8-13 Hz yang muncul ketika seseorang terbangun atau sedang beristirahat dengan rileks, sehingga gelombang ini berperan dalam kemunculan rasa segar, tenang dan rileks (Tortora \& Derrickson, 2010). Penelitian yang dilakukan oleh Zulkurnaini, Kadir, Murat, \& Isa (2012), Al-Galal \& Alshaikhli (2017), Shekha, Hassan, Othman, Hassan, \& Othman (2013) menjelaskan bahwa mendengarkan murattal Alquran dapat memunculkan gelombang alpa di otak yang membuat seseorang merasa tenang dan rileks. Gelombang alpa yang ditimbulkan setelah mendengarkan murattal Alquran lebih tinggi dibandingkan ketika seseorang mendengarkan musik relaksasi (Al-Galal \& Alshaikhli, 2017; Shekha et al., 2013).

Murattal Alquran merupakan lantunan ayat Alquran yang dibacakan dengan bacaan yang tartil dan sesuai kaidah dalam ilmu tajwid (Nelson, 2001). Mahjoob, Nejati, Hosseini, \& Bakhshani (2016) menerangkan bahwa mendengarkan Alquran dapat memberikan efek positif pada kesehatan mental dan mampu menaikkan kesehatan mental pendengarnya. Sejalan dengan penelitian tersebut, penelitian Julianto \& Subandi (2015) menunjukkan bahwa membaca Al-Fatihah dapat menurunkan stres dan meningkatkan imunitas seseorang. Murattal Alquran juga dapat meningkatkan pembentukan endorfin sehingga membuat relaksasi otot terjadi (Irawati \& Lestari, 2017; Julianto, Dzulqaidah, \& Salsabila, 2016). Jika dibandingkan dengan mendengarkan musik atau suara-suara alam lainnya, efek dari mendengarkan Alquran memiliki dampak yang lebih tahan lama dalam memberikan ketenangan dan mengurangi stres, terlebih jika dilakukan terus menerus (Khan et al., 2010).

Alquran memiliki caranya tersendiri untuk membuat manusia mengingat Tuhannya. Ayat-ayat di dalam Alquran banyak terdiri atas doa-doa dan kebersyukuran. Oleh karena itu, membaca dan mendengarkan Alquran dapat menjadi salah satu metode untuk berdoa dan mendekat kepada Tuhan. Hal ini dapat membuat jiwa manusia tenang karena mendapatkan kekuatan spiritual untuk kesehatan jiwa (Hamidi, Bagherzadeh, \& Gafarzadeh, 2010). Bacaan Alquran juga dapat menjadi pengobatan medis dan memengaruhi kondisi spiritual dan kesehatan mental seseorang (Pashib, Khaqani, Bahrainian, \& Abedi, 2014). Membaca Al-Qur'an dapat menjadi salah satu cara pengobatan bagi gangguan mental (Kazemi, Ansari, 
Tavakoli, \& Karimi, 2003) karena religiusitas dan keyakinan yang mendalam pada Alquran, yang di dalamnya penuh dengan doa-doa, dapat membantu seseorang meraih ketenangan dan kesehatan dari berbagai penyakit (Atarodi, Mottaghi, \& Atarodi, 2012). Selain bertujuan untuk beribadah dan meningkatkan ketakwaan kepada Allah, membaca dan mendengarkan Alquran dapat menjadi salah satu cara untuk menenangkan diri dan menurunkan tingkat stres maupun depresi yang dialami seseorang.

Akan tetapi, berbagai penelitian yang ada cenderung dilakukan pada subjek yang sedang dalam masa pengobatan medis, pasien rawat inap di rumah sakit, dan berada pada rentang usia dewasa akhir sampai lansia. Masih jarang ditemukan penelitian dalam bidang psikologi yang menggunakan individu sehat dan normal secara medis sebagai subjek penelitian untuk melihat pengaruh murattal Alquran terhadap stres di Indonesia, khususnya di Yogyakarta. Oleh karena itu, penelitian ini dilakukan untuk melihat pengaruh murattal Alquran terhadap tingkat stres yang dialami individu sehat secara medis, khususnya pada mahasiswa di Yogyakarta.

\section{Metode}

Desain penelitian

Desain penelitian ini adalah randomized pretest and posttest control group design. Pada desain ini, terdapat dua kelompok, yaitu kelompok eksperimen dan kelompok kontrol, dengan pembagian subjek dalam setiap kelompok dilakukan secara acak. Hal tersebut dilakukan agar validitas internal dari eksperimen terjaga dan mengurangi bias antar subjek eksperimen (Shadish, Cook, \& Campbell, 2001).

\section{Subjek penelitian}

Penelitian ini diikuti oleh 30 subjek perempuan dan 15 subjek laki-laki $(n=$ 45), yang merupakan mahasiswa S1 angkatan 2015 - 2017 dari beberapa universitas di Yogyakarta dengan kriteria: 1) usia 18-22 tahun; 2) beragama Islam; 3) tidak sedang dalam pengobatan medis; 4) tidak memiliki trauma/riwayat gangguan psikologis; 5) jarang/tidak pernah membaca dan/atau mendengarkan Alquran; 6) bersedia mengikuti eksperimen. Komposisi subjek pada tiap kelompok disajikan dalam tabel 1 .

Tabel 1.

Komposisi Subjek Tiap Kelompok

\begin{tabular}{lcc}
\hline Kelompok & Jumlah $(\boldsymbol{n})$ & $\begin{array}{c}\text { Persentase } \\
(\mathbf{\%})\end{array}$ \\
\hline Eksperimen & 23 & $51,11 \%$ \\
\hline Kontrol & 22 & $48,89 \%$ \\
\hline Total & 45 & $100 \%$ \\
\hline
\end{tabular}

Instrumen penelitian

Skala DASS subskala stres digunakan untuk mengukur tingkat stres subjek sebelum dan setelah diberi perlakuan. Aspek-aspek yang diukur oleh skala ini didasarkan atas teori stres dari Hans Selye, antara lain kesulitan untuk rileks, kegelisahan, mudah kecewa, mudah marah, dan rasa tidak sabar (Lovibond \& Lovibond, 1995b). Skala ini telah diadaptasi ke dalam bahasa Indonesia oleh Damanik (2011) dan diuji reliabilitasnya dengan koefisien reliabilitas alpha Cronbach sebesar 0,8806 $(p>0,05)$.

\section{Prosedur penelitian}

Penelitian dilaksanakan pada pada 3 hari yang berbeda dan di dilaksanakan pada pagi hari. Dalam prosesnya, peneliti menggunakan dua ruang bersebelahan yang dipisahkan oleh sebuah pintu yang ada di dalam ruangan. Setiap ruang memiliki 10 komputer yang ada di dalam 
sekat-sekat kecil berukuran 1x1 meter, pendingin ruangan, dan beberapa meja yang terletak di tengah setiap ruangan. Setiap bilik dilengkapi dengan 1 set komputer, kursi, dan sebuah headphone.

Penelitian ini tentu tidak lepas dari variabel extraneous, yaitu variabel eksternal dalam sebuah penelitian yang memiliki kemungkinan memengaruhi hasil dari penelitian tersebut, meski tidak memiliki hubungan dengan variabel yang digunakan dalam penelitian (Shaughnessy, Zechmeister, \& Zechmeister, 2012), seperti kondisi lingkungan yang bising, cara penyampaian instruksi yang tidak sama antar subjek, dan efek belajar pada subjek terhadap skala yang diberikan sebelum dan setelah diberi perlakuan. Kondisi tersebut dikendalikan dengan menempatkan subjek pada bilik-bilik komputer yang memiliki headphone dan membatasi interaksi subjek dengan subjek lainnya, sehingga ruangan kondusif dan tenang untuk menjalankan penelitian. Selain itu, pengacakan aitem skala yang diisi melalui komputer sudah diacak secara otomatis untuk mengurangi efek belajar terhadap skala. Eksperimenter juga diberikan lembar instruksi untuk memastikan standardisasi dalam penyampaian instruksi awal agar subjek mendapatkan penjelasan penelitian yang terstandar.

Kedua kelompok diminta untuk mengisi pretest yaitu skala stres yang diambil dari skala DASS oleh Lovibond \& Lovibond (1995a). Setelah itu, kelompok eksperimen diberikan perlakuan berupa mendengarkan murattal Alquran dengan surat pilihan yaitu surat Ar-Rahman yang dilantunkan oleh Qari' Mishary Rasyid Alfasy selama kurang lebih 12 menit menggunakan headphone yang tersedia. Sedangkan kelompok kontrol tidak mendapat perlakuan apapun dan diminta untuk menunggu instruksi berikutnya.

Ketika kelompok eksperimen telah selesai mendengarkan murattal Alquran, kedua kelompok diminta untuk mengisi posttest berupa skala yang sama dengan posttest. Di akhir eksperimen, kelompok eksperimen juga diminta untuk menuliskan kesan selama mengikuti penelitian sebagai data tambahan.

\section{Analisis}

Hasil skor yang didapatkan dari pretest dan posttest dianalisis menggunakan Mixed ANOVA. Mixed ANOVA digunakan karena penelitian ini memiliki variabel terikat yang dianalisis dalam 2 kelompok berbeda, serta terdapat manipulasi pada variabel bebas (Field, 2007). Selain itu, hasil dari analisis dapat menunjukkan perbedaan skor dalam satu kelompok (within subject) yaitu skor pretest dan posttest, serta menunjukkan perbedaan skor antar kelompok eksperimen dan kelompok kontrol (between subject) (Aron, Coups, \& Aron, 2013).

\section{Hasil}

Deskripsi data penelitian

Skor rata-rata pada kelompok eksperimen

Tabel 2.

Deskripsi Data Penelitian

\begin{tabular}{lllllllll}
\hline \multirow{2}{*}{ Skor } & \multicolumn{4}{c}{ Eksperimen } & \multicolumn{5}{c}{ Kontrol } \\
\cline { 2 - 10 } & Mean & SD & Max & Min & Mean & SD & Max & Min \\
\hline Pretest & 21,04 & 5,740 & 34 & 15 & 22,50 & 5,747 & 37 & 16 \\
\hline Posttest & 15,09 & 7,204 & 36 & 2 & 21,36 & 6,276 & 36 & 12 \\
\hline
\end{tabular}


dan kontrol tidak berbeda jauh saat pretest (lihat tabel 2). Akan tetapi, terdapat perbedaan yang cukup jauh pada rata-rata skor posttest antar kelompok yaitu 15,09 untuk kelompok eksperimen dan 21,36 untuk kelompok kontrol.

Tabel 3.

Uji Normalitas

\begin{tabular}{llcc}
\hline \multirow{2}{*}{ Kelompok } & \multirow{2}{*}{ Skor } & \multicolumn{2}{c}{ Shapiro-Wilk } \\
\cline { 2 - 4 } & & Statistik & Sig. $(p)$ \\
\hline \multirow{2}{*}{ Eksperimen } & Pretest & 0,874 & 0,008 \\
\cline { 2 - 4 } & Posttest & 0,950 & $0,291^{*}$ \\
\hline \multirow{2}{*}{ Kontrol } & Pretest & 0,918 & $0,068^{*}$ \\
\cline { 2 - 4 } & Posttest & 0,946 & $0,260^{*}$ \\
\hline
\end{tabular}

Ket $:{ }^{*}=\operatorname{normal}(p>0,05)$

Standar deviasi pada setiap kelompok tidak memiliki perbedaan yang begitu mencolok pada skor pretest maupun posttest. Pada skor pretest, kelompok eksperimen memiliki standar deviasi sebesar 5,740 dan kelompok kontrol memiliki standar deviasi sebesar 5,747. Pada skor posttest didapatkan standar deviasi sebesar 7,204 untuk kelompok eksperimen dan 6,276 untuk kelompok kontrol.

Uji asumsi normalitas dan homogenitas

Uji normalitas dilakukan untuk melihat kenormalan distribusi data yang digunakan dalam penelitian ini. Data dikatakan terdistribusi secara normal apabila taraf signifikansi lebih dari 0,05 ( $p$ $>0,05)$. Penelitian ini menggunakan uji normalitas Shapiro-Wilk karena data penelitian berjumlah kurang dari 50 (Mecklin, 2007). Hasil uji normalitas dapat dilihat di tabel 3.

Terlihat bahwa nilai $p$ pada skor pretest kelompok eksperimen 0,008 , pretest kelompok kontrol 0,068, posttest kelompok eksperimen 0.291, dan posttest kelompok kontrol 0,260. Data tersebut menunjukkan seluruh data terdistribusi secara normal ( $p$ $>0,05)$, kecuali untuk skor pretest pada kelompok eksperimen yang memiliki nilai $p$ kurang dari 0,05 $(p<0,05)$.

Ketidaknormalan data yang terjadi pada skor pretest kelompok eksperimen dapat diabaikan karena sesungguhnya ANOVA yang merupakan uji nilai $F$ kebal (robust) terhadap ketidaknormalan data (Ramsey, 2007).

Sedangkan uji homogenitas dilakukan untuk melihat varian dari data yang digunakan bersifat homogen atau tidak. Data dikatakan homogen apabila taraf signifikansi lebih dari 0,05 $(p>0,05)$ dan dikatakan tidak homogen apabila taraf signifikansi kurang dari 0,05 ( $p<$ $0,05)$. Uji homogenitas dalam penelitian ini menggunakan uji Levene dan disajikan dalam tabel 4 .

Tabel 4 .

Uji Homogenitas

\begin{tabular}{lll}
\hline Skor & $\boldsymbol{F}$ & Sig. $(p)$ \\
\hline Pretest & 0,004 & $0,947^{*}$ \\
\hline Posttest & 0,006 & $0,941^{*}$ \\
\hline Ket $:{ }^{*}=$ homogen $(p>0,05)$
\end{tabular}

Tabel 4 menunjukkan bahwa skor pretest memiliki taraf signifikansi sebesar 0,947 dan untuk skor posttest sebesar 0,941. Hasil ini menunjukkan bahwa data bersifat homogen $(p>0,05)$. 
Tabel 5.

Hasil Analisis Varian Skor Stres

\begin{tabular}{lllllll}
\hline Sumber & $\boldsymbol{J K}$ & $\boldsymbol{d} \boldsymbol{b}$ & $\boldsymbol{R} \boldsymbol{K}$ & $\boldsymbol{F}$ & Sig. & $\boldsymbol{E T A}^{2}$ \\
\hline Dalam Kelompok & & & & & & \\
SkorStres & 282,849 & 1 & 282,849 & 22,449 & 0,000 & 0,343 \\
SkorStres Kelompok & 130,626 & 1 & 130,626 & 10,386 & 0,002 & 0,194 \\
\hline Antar Kelompok & & & & & & \\
Kelompok & 168,111 & 1 & 168,111 & 5,081 & 0,029 & 0,106 \\
\hline
\end{tabular}

Tabel 6.

Perubahan Skor Stres

\begin{tabular}{lllcl}
\hline Kelompok & Waktu & Waktu & Perbedaan Rerata & Sig. \\
\hline Eksperimen & 2 & 1 & $-5,957$ & 0,000 \\
\hline Kontrol & 2 & 1 & $-1,136$ & 0,294 \\
\hline
\end{tabular}

\section{Uji hipotesis}

Pengujian hipotesis dilakukan dengan menggunakan teknik mixed ANOVA. Teknik ini dilakukan karena dapat melihat perbedaan skor tes yang diberikan pada waktu yang berbeda di dalam kelompok (within group), maupun antar kelompok (between group). Data yang digunakan untuk analisis adalah skor pretest-posttest kelompok eksperimen dan skor pretest-posttest kelompok kontrol. Hasil analisis dapat dilihat pada tabel 5 dan tabel 6.

Hasil pada tabel 5 menunjukkan nilai $F$ sebesar 10,386 dengan taraf signifikansi 0,002. Hal ini menunjukkan bahwa terdapat interaksi terhadap skor stres dengan kelompok dan terdapat perbedaan yang signifikan antara kelompok eksperimen dengan kelompok kontrol $(p<0,05)$ dan memberi sumbangan efektif sebesar 19,4\% (ETA2 = 0,194). Selain itu, terdapat perbedaan perubahan skor stres yang ada dalam kelompok dengan skor $F$ sebesar 22,449 ( $p$ $<0,05)$. Perbedaan skor stres antar kelompok juga ditunjukkan dengan skor $F$ sebesar 5,081 dan signifikansi 0,029 ( $p<$ 0,05). Hal ini menunjukkan bahwa murattal Alquran terbukti memiliki pengaruh yang signifikan terhadap tingkat stres dan hipotesis penelitian diterima.

Di sisi lain, tabel 6 menunjukkan perbedaan rata-rata dan taraf signifikansi skor pretest dan posttest pada kelompok eksperimen dan kelompok kontrol. Perbedaan rata-rata didapatkan dengan mengurangi rata-rata skor pada waktu 2 (posttest) dan waktu 1 (pretest). Perbedaan rata-rata kelompok eksperimen adalah sebesar -5,957 dengan taraf signifikansi kurang dari 0,05 dan pada kelompok kontrol sebesar -1,136 dengan taraf signifikansi 0,294. Artinya, terdapat penurunan pada skor posttest kedua kelompok. Akan tetapi, penurunan skor pada kelompok eksperimen lebih signifikan $(p<0,05)$ dibandingkan kelompok kontrol $(p>0,05)$.

\section{Diskusi}

Stres adalah kondisi ketika seseorang merasa tegang, gelisah, sulit rileks, sensitif, pusing, takut, kehilangan nafsu makan, sulit tidur di malam hari (Alatas, 2017). Secara psikologis, Brannon et al., (2013) menjelaskan bahwa ada tiga cara yang dapat digunakan untuk melakukan manajemen stres, yaitu dengan berlatih relaksasi, terapi kognitif keperilakuan, 
dan penyingkapan emosi, baik emosi positif maupun negatif.

Murattal Alquran merupakan salah satu teknik relaksasi yang memberikan ketenangan dan memulihkan tubuh karena memiliki pengaruh religiusitas dan keimanan yang terlibat dalam penurunan kecemasan, depresi, dan dapat memperbaiki kualitas tidur (Suryani \& Salmiyati, 2016). Selain itu, penelitian ini tidak hanya meminta subjek untuk mengisi skala stres, namun subjek eksperimen juga diminta untuk menuliskan kesannya setelah mengikuti eksperimen sebagai bentuk dari salah satu manajemen stres dalam proses personal healing berupa penyingkapan emosi (emotion disclosure) dengan aktivitas menulis (Brannon et al., 2013).

Emosi positif yang dirasakan setelah mendengarkan murattal Alquran terjadi pada beberapa subjek. Ada subjek yang sedang merasa sangat sedih dan pusing, namun perasaannya berubah menjadi lebih tenang dan damai setelah mendengarkan murattal Alquran. Subjek juga merasa bahwa ada yang menjaganya dari berbagai permasalahan, sehingga ketenangan itu muncul. Ketenangan yang muncul disebabkan oleh terangsangnya sistem auditori yang meningkatkan pembentukan hormon endorfin dan menimbulkan efek relaksasi (Julianto et al., 2016) dan juga memunculkan pemikiran positif akan hidup (Julianto \& Subandi, 2015). Hasil ini sejalan pula dengan penelitian yang dilakukan oleh Zahra \& Saidiyah (2013) bahwa murattal Alquran dapat menurunkan stres yang dialami mahasiswa dan penelitian Zulkurnaini et al., (2012), Al-Galal \& Alshaikhli, (2017), dan Shekha et al., (2013) yang menjelaskan bahwa mendengarkan murattal Alquran dapat memunculkan gelombang alpa di otak yang membuat seseorang merasa tenang dan rileks.
Di sisi lain, emosi negatif pun ditunjukkan dari kesan subjek yang menceritakan bahwa ia sempat merasa rileks di awal, namun ia merasa sedih dan takut di akhir sesi eksperimen. Najati (1985) menjelaskan bahwa sering kali perasaan takut muncul bersamaan dengan rasa sedih. Rasa sedih dan takut yang terjadi dapat disebabkan karena seorang individu mengingat kesalahan, takut akan dosa-dosa yang telah diperbuat, dan takut terhadap ujian dan azab yang mungkin diberikan oleh Allah, sehingga merasa kembali terhubung dengan Sang Pencipta (Awa, 2014).

Hal tersebut juga ditunjukkan oleh Subjek 5 yang menuliskan kesan bahwa ia merupakan individu yang mudah cemas. Akan tetapi selama mendengarkan murattal Alquran, ia menyadari bahwa kecemasan tersebut muncul karena sikapnya yang kurang dekat dengan Allah, sehingga menyebabkan dirinya kurang bersyukur dan kurang ikhlas dalam menerima hal-hal yang terjadi dalam hidupnya.

Murattal Alquran juga dapat memunculkan kembali ingatan akan kesalahan diri sendiri dan dosa-dosa yang telah diperbuat. Ketika seseorang kembali ingat pada kesalahannya, akan ada keinginan untuk mengakui kesalahan dan berusaha memaafkan diri sendiri seperti yang dirasakan oleh salah satu subjek. Subjek tersebut mengatakan bahwa setelah mendengarkan murattal Alquran, ia teringat akan suatu hal. Di akhir kalimat, ia berdoa agar Allah mengampuni dosa-dosa kita.

Perasaan sedih, takut, cemas, dan gelisah menjadi penting bagi kesehatan mental seorang muslim karena membuatnya terhubung dengan Tuhan (al-Domi, 2015). Ketika seseorang tidak terhubung dengan dirinya sendiri, Tuhan, dan kehidupannya, ia akan menjadi individu yang mudah takut, marah, 
cemas, dan depresi (Warber, 2011 dalam Awa, 2014). Perasaan tersebut juga dapat membuatnya kembali kepada Allah, melaksanakan perintah-Nya, menjauhi larangan-Nya, dan membuat terealisasikannya kedamaian psikis karena memunculkan pengharapan akan ampunan dan keridhaan Allah (Najati, 1985). Hal ini juga dijelaskan di dalam Alquran Surat Az-Zumar ayat 23 yang berbunyi:

"Allah telah menurunkan perkataan yang paling baik (yaitu) Al Quran yang serupa (mutu ayat-ayatnya) lagi berulang-ulang, gemetar karenanya kulit orang-orang yang takut kepada Tuhannya, kemudian menjadi tenang kulit dan hati mereka di waktu mengingat Allah."

Terlebih lagi, penyingkapan emosi seperti takut, sedih, dan emosi lainnya yang muncul setelah ada kejadian negatif bisa jadi berujung pada aktivitas menangis (alDomi, 2015). Menangis karena takut pada Allah menjadi sebuah hal penting bagi umat muslim. Menangis memiliki efek terapeutik yang dapat digunakan untuk melepaskan rasa stres, depresi, ketakutan, dan frustrasi terhadap berbagai tekanan hidup (al-Domi, 2015). Seperti yang di dijelaskan dalam Alquran Surat Maryam ayat 58 yang berbunyi:

"Apabila dibacakan ayat-ayat Allah Yang Maha Pemurah kepada mereka, maka mereka menyungkur dengan bersujud dan menangis."

Penelitian ini dilakukan pada subjek yang tidak memiliki penyakit secara medis maupun psikologis, jarang mendengarkan murattal Alquran, dan memiliki tingkat stres ringan hingga berat. Tingkat stres subjek menurun setelah mendengarkan murattal Alquran.
Koneksi pada Tuhan yang ditimbulkan dari mendengarkan murattal Alquran menjadi komponen penting yang dimiliki oleh murattal Alquran karena melalui hal tersebut subjek dapat merasa tenang, merasa hidupnya terjaga dari berbagai permasalahan, menimbulkan kesadaran akan kondisi diri yang perlu diperbaiki, dan juga memunculkan pengharapan pada Tuhan. Murattal Alquran juga memiliki nilai-nilai religius dan rohani dari Alquran yang dapat mengatasi tekanan dan ketegangan yang dirasakan manusia (Najati, 1985). Berbagai penelitian pun mendukung hasil dari penelitian ini. Dengan demikian, pemberian murattal Alquran terbukti berpengaruh terhadap perubahan tingkat stres dengan memberikan efek terapeutik berupa perasaan tenang, nyaman, dan rileks.

\section{Kesimpulan}

Hasil analisis yang dilakukan menunjukkan bahwa terdapat pengaruh dari murattal Alquran terhadap perubahan tingkat stres. Selain itu, terdapat perbedaan perubahan tingkat stres antar subjek yang mendengarkan dan tidak mendengarkan murattal Alquran. Tingkat stres subjek yang mendengarkan murattal Alquran menurun secara signifikan. Hal ini terjadi karena setelah mendengarkan murattal Alquran, subjek merasa tenang, rileks, damai, dan semakin terkoneksi dengan Tuhan. Dengan demikian, mendengarkan murattal Alquran dapat dijadikan sebagai alternatif self-healing maupun relaksasi yang murah, mudah, dan aman bagi masyarakat untuk meningkatkan kesehatan mental dan mengurangi stres dalam kehidupan sehari-hari. 
Saran

Masyarakat dapat menjadikan penelitian ini sebagai salah satu wawasan terkait manfaat murattal Alquran dan dapat mulai mencoba untuk menerapkannya dalam kehidupan sehari-hari dengan rutin mendengarkan murattal Alquran. Hal ini diharapkan dapat menjadi salah satu langkah kecil yang dapat berdampak besar dalam kesehatan mental masyarakat Indonesia.

Peneliti selanjutnya sebaiknya melakukan penelitian lebih mendalam dengan mewawancarai subjek untuk dapat melihat dinamika psikologis yang terjadi pada subjek juga melakukan pemaknaan mendalam terhadap ayat yang diberikan sebagai intervensi. Selain itu, peneliti selanjutnya juga dapat mengidentifikasi karakteristik suara yang ada pada murattal Alquran secara lebih mendalam, atau menggunakan gaya membaca mujawwad dengan beragam jenis dan pelantunnya.

\section{Kepustakaan}

al-Domi, M. M. (2015). The cry in the holy Quran and the effect on the human behaviour. Journal of Education and Practice, 6(20), 52-61.

Alatas, M. (2017). Pengaruh terapi murottal surah Ar-Rahman terhadap skor pengkajian luka (mungs) dan pengkajian stres (DASS) pada pasien diabetes mellitus di Klinik Kitamura Pontianak. Proners, 3(1), 1-17.

Al-Galal, S. A. Y., \& Alshaikhli, I. F. T. (2017). Analyzing brainwaves while listening to Quranic recitation compared with listening to music based on EEG signals. International Journal on Perceptive and Cognitive Computing, 3(1), 1-5. doi: $\underline{10.31436 / \text { ijpcc.v3i1.43 }}$
Aron, A., Coups, E. J., \& Aron, E. (2013). Statistics for psychology. Boston: Pearson.

Atarodi, A. R., Mottaghi, M. R., \& Atarodi, F. (2012). Comparative study on the effect of prayer and praise on peace of mind and physical health from male and female students' points of view in Gonabad's guidance schools in 1390. Islamic Lifestyle Centered on Health, 1(2), 28-33.

Awa, S. (2014). Effects of holy Quran listening on physiological stress response among muslim patients in intensive care unit. E-proceedings of the Conference on Management and Muamalah. 164-172.

Brannon, L., Feist, J., \& Updegraff, J. A. (2013). Health psychology: An introduction to behavior and health (Edisi kedelapan). USA: Cengage Learning.

Damanik, E. D. (2011). The measurement of reliability, validity, items analysis and normative data of depression anxiety stress scale (DASS). Diunduh dari http://www2.psy.unsw.edu.au/dass/ Indonesian/Damanik\%20Indonesian \%20translation\%20\%20Reliability.doc

Field, A. P. (2007). Analysis of variance (ANOVA). In N. J. Salkind \& K. Rasmussen (Eds.), Encyclopedia of measurement and statistics. Thousand Oaks, Calif: SAGE Publications.

Grayson, P. A., \& Meilman, P. W. (Eds.). (2006). College mental health practice. United States: Routledge.

Hamidi, F., Bagherzadeh, Z., \& Gafarzadeh, S. (2010). The role of Islamic education in mental health. Procedia - Social and Behavioral Sciences, 5, 1991-1996.

Irawati, P., \& Lestari, M. S. (2017). Pengaruh membaca Alquran terhadap penurunan tekanan darah 
pada klien dengan hipertensi di RSK Dr. Sitanala Tangerang. Jurnal Ilmiah Keperawatan Indonesia (JIKI), 1(1), 3545.

Julianto, V., Dzulqaidah, R. P., \& Salsabila, S. N. (2016). Pengaruh mendengarkan murattal Al Quran terhadap peningkatan kemampuan konsentrasi. Psympathic: Jurnal Ilmiah Psikologi, 1(2), 120-129. doi: 10.15575/psy.v1i2.473

Julianto, V., \& Subandi. (2015). Membaca Al Fatihah reflektif intuitif untuk menurunkan depresi dan meningkatkan imunitas. Jurnal Psikologi, 42(1), 34-46. doi: 10.22146/jpsi.6941

Kazemi, M., Ansari, A., Tavakoli, M. A., \& Karimi, S. (2003). The effect of the recitation of Holy Quran on mental health in nursings students of Rafsanjan University of Medical Sciences. Journal of Rafsanjan University of Medical Science and Health Services, 3(1), 52-57.

Khan, N., Ahmad, N. bt, Beg, A. H., Fakheraldin, M. A. I., Alla, A. N. A., \& Nubli, M. (2010). Mental and spiritual relaxation by recitation of the Holy Quran. 2010 Second International Conference on Computer Research and Development, 863-867. doi: 10.1109/ICCRD.2010.62

Lovibond, S. H., \& Lovibond, P. F. (1995a). Manual for depression anxiety stress scales (Edisi kedua). Sydney: Psychology Foundation.

Lovibond, S. H., \& Lovibond, P. F. (1995b). The structure of negative emotional states: comparison of the depression anxiety stress scales (DASS) with the beck depression and anxiety inventories. Behaviour Research and Therapy, 3(3), 335-343. doi: 10.1016/0005-7967(94)00075-u

Mahjoob, M., Nejati, J., Hosseini, A., \& Bakhshani, N. M. (2016). The effect of Holy Quran voice on mental health. Journal of Religion and Health, 55(1), 38-42. doi: 10.1007/s10943-0149821-7

Mecklin, C. J. (2007). Shapiro-Wilk test for normality. In N. J. Salkind \& K. Rasmussen (Eds.), Encyclopedia of measurement and statistics (pp. 883885). Thousand Oaks, Calif: SAGE Publications.

Muhtadi, B., \& Prasetyo, H. (18 Desember 2017). Agama, Kesalehan Ritual, dan Korupsi. Diunduh pada 23 Juni 2018, dari situs Media Indonesia: http://mediaindonesia.com/read/det ail/136880-agama-kesalehan-ritualdan-korupsi

Najati, D. M. 'Utsman. (1985). Al Qur'an dan Ilmu jiwa (A. R. 'Usmani, Trans.). Bandung: Penerbit PUSTAKA.

Nelson, K. (2001). The art of reciting the Qur'an. Cairo ; New York: American University in Cairo Press.

Pashib, M., Khaqani, F., Bahrainian, A., \& Abedi, A. (2014). Investigation of the effectiveness of Quran recitation. Journal of Applied Environmental and Biological Science, 4(12), 137-140.

Ramsey, P. H. (2007). Factorial design. In N. J. Salkind (Ed.), Encyclopedia of measurement and statistics (Vol. 2). USA: SAGE Publications.

Ruhmadi, E., Suwartika, I., \& Nurdin, A. (2014). Analisis faktor yang berhubungan dengan tingkat stress akademik mahasiswa reguler Program Studi D III Keperawatan Cirebon Poltekkes Kemenkes Tasikmalaya. Jurnal Keperawatan Soedirman, 9(3), 173-189. doi: 10.20884/1.jks.2014.9.3.612

Sadeghi, H. (2011). Voice of Quran and health: A review of performed studies in Iran. Quarterly of Quran $\mathcal{E}$ Medicine, 1(1), 33-337.

Santrock, J. W. (2014). A topical approach to life-span development (Edisi ketujuh). 
New York, NY: McGraw-Hill Education.

Shadish, W. R., Cook, T. D., \& Campbell, D. T. (2001). Experimental and quasiexperimental designs for generalized causal inference. Boston: Houghton Mifflin.

Shaughnessy, J. J., Zechmeister, E. B., \& Zechmeister, J. S. (2012). Research methods in psychology (Edisi kesembilan). New York, NY: McGraw-Hill.

Shekha, M. S., Hassan, A. O., Othman, S. A., Hassan, A. O., \& Othman, S. A. (2013). Effects of Quran listening and music on electroencephalogram brain waves. The Egyptian Journal of Experimental Biology (Zoology), 9(1), 119-121.

Suryani, S., \& Salmiyati, S. (2016). Pengaruh Terapi Audio Murottal Surah Ar Rahman terhadap Tingkat Insomnia Lansia. Fakultas Ilmu Kesehatan Universitas 'Aisyiyah Yogyakarta.
Taylor, S. E. (2015). Health psychology (Edisi kesembilan). New York, NY: McGraw-Hill Education.

Tortora, G. J., \& Derrickson, B. (2010). Principles of anatomy and physiology (Edisi kedua belas). Hoboken, NJ: John Wiley \& Sons.

Zahra, A. A., \& Saidiyah, S. (2013). Efektivitas pelatihan pemaknaan surat Al-Insyirah untuk mengurangi stres mahasiswa yang sedang mengerjakan skripsi. JIP: Jurnal Intervensi Psikologi, 5(1), 25-42. doi: 10.20885/intervensipsikologi.vol5.iss 1.art2

Zulkurnaini, N. A., Kadir, R. S. S. A., Murat, Z. H., \& Isa, R. M. (2012, February). The Comparison between Listening to Al-Quran and Listening to Classical Music on the Brainwave Signal for the Alpha Band. 2012 Third International Conference on Intelligent Systems Modelling and Simulation, 181-186. doi: $\underline{10.1109 / \text { ISMS.2012.60 }}$ 